\title{
Supporting Information for Langmuir
}

\section{Surface Modification of Polyacrylonitrile-based Membranes by Chemical Reactions to Generate Phospholipid Moieties}

\author{
Xiao-Jun Huang ${ }^{1}$, Zhi-Kang Xu ${ }^{1}{ }^{1 *}$, Ling-Shu Wan ${ }^{1}$, Zhen-Gang Wang ${ }^{1}$, Jian-Li Wang ${ }^{2}$ \\ ${ }^{1}$ Institute of Polymer Science, Zhejiang University, Hangzhou 310027, P. R. China \\ ${ }^{2}$ College of Chemical Engineering and Materials, Zhejiang University of Technology, \\ Hangzhou 310014, P. R. China \\ *Corresponding author. Fax: ++ 865718795 1773; e-mail: xuzk@ipsm.zju.edu.cn
}

Table 1. Typical Characteristics of the studied porous membranes

\begin{tabular}{lccc}
\hline Sample no. & $\begin{array}{c}\text { Thickness } \\
(\mu \mathrm{m})\end{array}$ & $\begin{array}{c}\text { Porosity ratio } \\
P_{r}(\%)^{a}\end{array}$ & $\begin{array}{c}\text { Water permeability } \\
J_{w}\left(\mathrm{~L} /\left(\mathrm{m}^{2} \mathrm{~h}\right)\right)^{\mathrm{b}}\end{array}$ \\
\hline PAN & $118 \pm 5$ & 76.6 & 320 \\
$\begin{array}{l}\text { PANCHEMA } \\
\text { (HEMA = 9.3 mol\%) }\end{array}$ & $115 \pm 5$ & 74.3 & 369 \\
$\begin{array}{l}\text { PMANCP } \\
(\text { phospholipid }=9.19 \mathrm{~mol} \%)\end{array}$ & $120 \pm 5$ & 78.7 & 483 \\
\hline
\end{tabular}

(a): $P_{r}=\left(\mathrm{w}_{1}-\mathrm{w}_{2}\right) / s l d_{\text {water }} \times 100 \%$. $\mathrm{w}_{1}$ and $\mathrm{w}_{2}$ represents the weight of the dried membrane and the membrane soaked in water for $24 \mathrm{~h}$, respectively. $s, l$, and $d$ represents the effective area, membrane thickness, and water density, respectively. (b): The filtration test was conducted at a constant transmembrane pressure of $0.1 \mathrm{MPa}$ and a system temperature of $22 \pm 0.5{ }^{\circ} \mathrm{C}$. The standard deviation was about $\pm 5 \%$. 


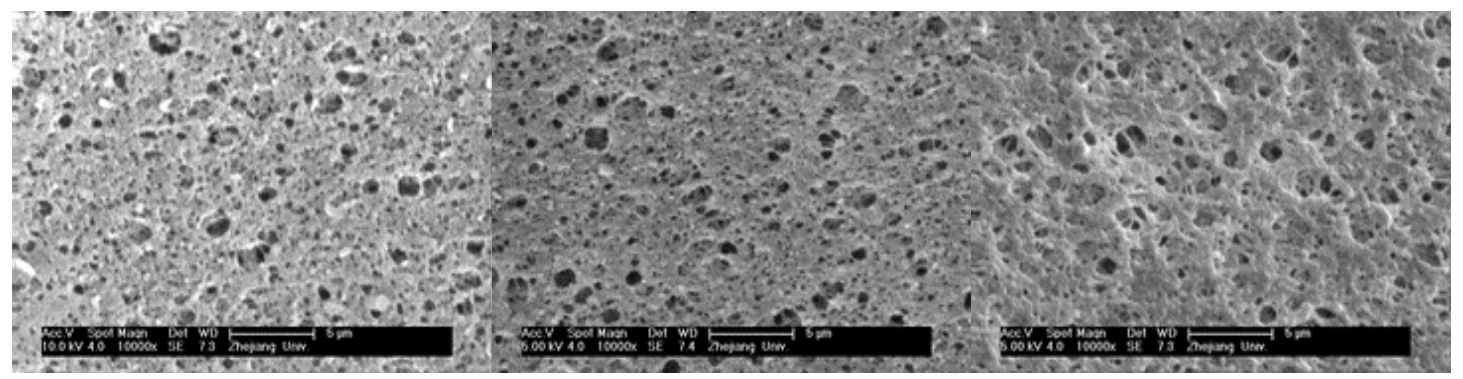

(a)

(b)

(c)

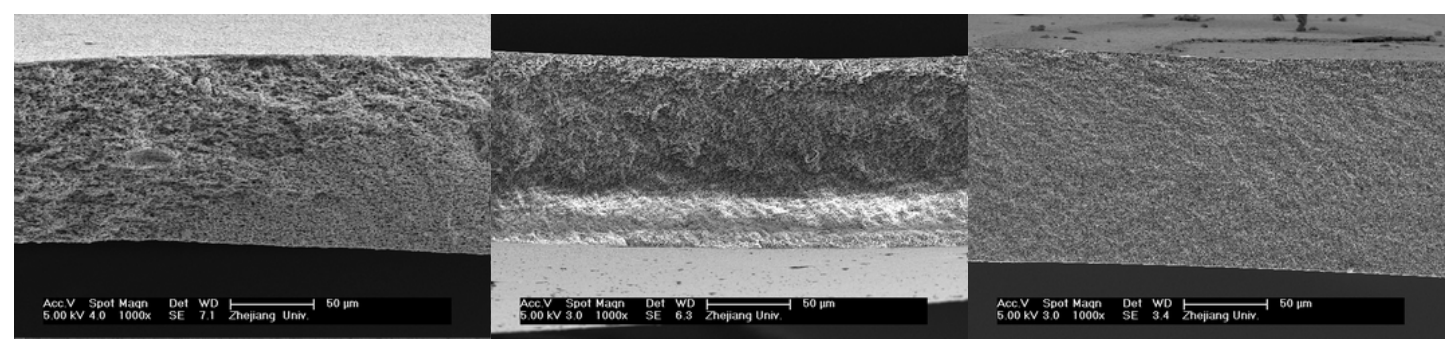

(d)

(e)

(f)

Figure 1. SEM photographs of the studied porous membrane surface ((a), (b) and (c)) and cross-section ((d), (e) and (f)): (a) and (d) PAN; (b) and (e) PANCHEMA (HEMA = 9.3 mol\%); (c) and (f) PMANCP (phospholipid $=9.19 \mathrm{~mol} \%$ ) 